\title{
Comments on Stuart Twemlow's "Misidentified Flying Objects? An Integrated Psychodynamic Perspective on Near-Death Experiences and UFO Abductions"
}

\author{
Keith Basterfield \\ Modbury North, Australia
}

\begin{abstract}
In addition to the hypotheses on UFO abductions and neardeath experiences described by Stuart Twemlow, another one has been put forward by researchers over the years that increases the complexity of the question of the reality of these experiences. Furthermore, there is some claimed physical evidence for abductions, while there is none for near-death experiences (NDEs). The exploration of unusual personal changes at the time of an abduction or NDE certainly warrants further attention, but investigators should give the well-being of the experiencer top priority.
\end{abstract}

Stuart Twemlow is to be congratulated for putting forward another viewpoint on near-death experiences (NDEs) and unidentified flying object (UFO) abductions. I have four comments on his approach to these anomalous phenomena.

First, Twemlow is quite correct that a major focus of research has been the attempted determination of the reality of both UFO abductions and NDEs. My findings from interviewing experiencers of both these anomalous phenomena clearly indicated that the experiencers themselves accept these episodes as "really real," as real as their consensus wakefulness experiences. Twemlow divided hypotheses on

Keith Basterfield has investigated both near-death and UFO experiences. Requests for reprints should be addressed to Mr. Basterfield at P. O. Box 302, Modbury North, South Australia 5092, Australia. 
this question into four positions: (1) that these experiences are totally internal or subjective; (2) that they are totally external or objective; (3) that they are mythic; or (4) his proposed integrated psychodynamic approach.

I suggest that there is at least one other perspective, which has been widely debated in different forms. British paranormal researcher and author Jenny Randles has long argued that UFOs are neither totally objective nor totally subjective (Randles, 1990). She suggested that UFOs might exist in an in-between state; they might sometimes become more physical and at other times more subjective. Elsewhere she postulated: "What we experience as an abduction in a vision. It is not really happening, yet is is far more than a mere hallucination" (Randles, 1988, p. 222).

American psychologist Kenneth Ring, who has had a long interest in NDEs and more recent interest in UFO abductions, has invoked the "imaginal world," a place perceived by psychologically sensitive individuals. This "imaginal world" is not imaginary, but has form, dimension, and persons in it (Ring, 1992). Jacques Vallee, a longterm supporter of the scientific study of UFOs, wrote (1990a, p. 224): "I believe that a UFO is both a physical entity ... and a window into another reality." Furthermore, he suggested (1990a, p. 224): "I propose to regard the UFO phenomenon as a physical manifestation of a form of consciousness."

Viewing these anomalous experiences as partly subjective and partly objective increases the complexity of the subject matter and allows additional hypotheses and interpretations.

My second comment is that Twemlow's model as outlined does not address a crucial difference between NDEs and UFO abductions. Unlike NDEs, abduction accounts often include claims of physical evidence of the experience. Individuals reporting UFO abductions sometimes describe finding unusual scars on their bodies with no known cause. In addition there are claims of $x$-rays, computerized tomography scans, and magnetic resonance imaging scans indicating unusual foreign bodies in an experiencer's body, although such reports are few and not well documented. While this evidence is only suggestive and difficult to interpret, nevertheless it does exist, in contrast to the total realiance on verbal testimony in NDE accounts.

My third comment regards Twemlow's "guess" that, if abductees were more intensively studied, unusual personal changes might be found in their lives at the time of the experience. Certainly hints of this are present in the existing literature. This idea was intensively discussed by Scott Rogo, who wrote: "In my opinion all UFO abductions 
may contain hidden meanings and symbols which directly relate to psychological conflicts" (1985, p. 10).

An incident supporting this notion occurred in Australia in 1973. Maureen Puddy, in the presence of two UFO researchers, lapsed into unconsciousness and described being in a room with an entity, the victim of an abduction. This even occurred at a time when she was caring for an invalid husband, had a son ill in the hospital, and was herself believed to have a brain tumor.

Likewise, the first two alleged abductees I worked with were attempting to recall their UFO abduction experiences at the same time they were actively dealing with being adult survivors of childhood sexual abuse. This avenue of thought certainly warrants further investigation in two distinct types of abduction reports: (a) those describing a single abduction event, and (b) those from individuals who claim multiple abductions stretching back to their childhood. Perhaps in this latter category psychodynamic perspectives might play an important role.

My final and most important comment regards clinical implications. Based on my personal experience with alleged abductees, I agree with Twemlow that the therapist "must accept the patient's view of reality in a way that is nonjudgmental and neutral" in order to be helpful. Thus debate among UFO researchers assisting therapists as to the reality of an abduction must be tempered by placing the well-being of the experiencer ahead of "proof" of the reality of the phenomenon.

\section{References}

Randles, J. (1988), Abduction. London, England: Robert Hale.

Randles, J. (1990). Mind monsters. Wellingborough, England: Aquarian Press.

Ring, K. (1992). The omega project. New York, NY: William Morrow.

Rogo, D. S. (1985, July/August). Secret language of UFO abductions-a speculation. International UFO Reporter, 10(4), 8-11.

Vallee, J. (1990a). Dimensions. London, England: Sphere.

Vallee, J. (1990b). Confrontations. New York, NY: Ballantine. 